\title{
Histomorphological Changes in the Skin and Eye Induced by Sub-Chronic Exposure of Wistar Rats to 3G Cell Phone Radiation
}

\author{
Stephen Talba Diyong1, Emmanuel Vandi Tizhe ${ }^{2}$, Stephen Dasam Songden ${ }^{1}$ \\ ${ }^{1}$ Department of Physics, Faculty of Natural Sciences, University of Jos, Jos, Nigeria \\ ${ }^{2}$ Department of Veterinary Microbiology and Pathology, Faculty of Veterinary Medicine, University of Jos, Jos, Nigeria \\ Email: diyongstephen@gmail.com,comradevandi@yahoo.com, songdenstephen@gmail.com
}

How to cite this paper: Diyong, S.T., Tizhe, E.V. and Songden, S.D. (2018) Histomorphological Changes in the Skin and Eye Induced by Sub-Chronic Exposure of Wistar Rats to 3G Cell Phone Radiation. Open Journal of Biophysics, 8, 194-203. https://doi.org/10.4236/ojbiphy.2018.84015

Received: August 7, 2018

Accepted: October 5, 2018

Published: October 8, 2018

Copyright $\odot 2018$ by authors and Scientific Research Publishing Inc. This work is licensed under the Creative Commons Attribution International License (CC BY 4.0).

http://creativecommons.org/licenses/by/4.0/

(c) (i) Open Access

\begin{abstract}
The effects of electromagnetic radiation produced by a $3 \mathrm{G}$ cell phone (third-generation) on skin tissues and eyes were investigated in terms of histomorphological parameters. A total of 26 Wistar rats (2 weeks-old, each weighing $40 \mathrm{~g}$ at the time of experiment) were used. They were maintained under a control room with water and food continuously available. The animals were divided into two experimental groups: Group A (Exposed) and Group B (Control), each with 13 Wistar Rats kept inside a plexi cage. Group A was exposed to a $3 \mathrm{G}$ cell phone radiation while Group B the control group, was not. All animals were generally anesthetized with Ketamine injection and then decapitated. The skin tissue was excised from the dorsal area and eyes samples were taken from all the rats by enucleating of the eye balls, fixed in $10 \%$ neutral buffered formalin for a minimum of 72 hours before processing through a graded alcohol and xylene was used as a clearing agent, embedded in paraffin blocks. Tissues were sectioned at $5 \mu \mathrm{m}$ thick and routinely stained with hematoxylin/eosin. Mounted slides were examined and photographed using a light microscope. Mild to severe orthokeratotic parakeratosis was observed in the skin while eye revealed loss of striation in the sclera with necrosis of the layers of rods and cones in the retina of the exposed group. We conclude that sub chronic exposure to $3 \mathrm{G}$ cell phone radiation impaired the protective ability of the skin and also impaired accommodation.
\end{abstract}

\section{Keywords}

Histomorphology, Radiation, Mobile Phone

\section{Background of the Study}

Over the past several years, the rapidly increasing use of mobile phones has 
raised global concerns about the biological effects of exposure to radiofrequency (RF) radiation. Numerous studies have shown that exposure to electromagnetic fields (EMFs) can be associated with effects on the nervous, endocrine, immune, cardiovascular, hematopoietic and ocular systems [1].

Concern about human exposure to radiofrequency (RF) is not new. The conveniences and satisfaction derived in the use of Global System for Mobile communications (GSM) is being threatened by claims of adverse effects on human health by radiation coming from this device. This radiation belongs to the type called non-ionizing radiation, the health hazard of which remains debatable [2]. $3 \mathrm{G}$ which stands for third generation is a type of mobile phone technology that allows phone calls, text messages and accessing the internet.

However, the growth in the use of cellular phone has raised the concerns about the possible interaction between the electromagnetic fields (EMF) radiation and the biological effects on human tissues, particularly the brain and the human immune system. These concerns have induced a large volume of research studies. This effect has raised concerns about the public exposure to radiation emitted from cell phone and the possible interaction between the radio frequency (RF) electromagnetic radiation and the biological effects on human tissues, particularly the brain and the human immune system. Many research works provided evidences about the possible health effects such as; brain tumor, blood brain barrier (BBB) permeability function, sleep problems, cognitive function, DNA damage, immunity system function and stress reaction [3]. GSM is a cellular network, which means that when mobile phones connect to it by searching for cells in the immediate vicinity, it operates in a number of different carrier frequency ranges that is $900 \mathrm{MHz}$ or $1800 \mathrm{MHz}$ bands [4].

These bands were already allocated, the $850 \mathrm{MHz}$ and $1900 \mathrm{MHz}$ bands are used instead Regardless of the frequency selected by an operator; it is divided into timeslots for individual phones to be used. This allows eight full-rate or sixteen half-rate speech channels per radio frequency. These eight radio timeslots (or eight burst periods) are grouped into a Time division multiple access (TDMA) frame. Half rate channels use alternate frames in the same timeslot. The transmission power in the handset is limited to a maximum of 2 watts in GSM850/900 and 1 watt in GSM1800/1900. Code division multiple access (CDMA) is a channel access method used by various radio communication technologies. One of the basic concepts in data communication is the idea that it allows several transmitters to send information simultaneously over a single communication channel. This allows several users to share a band of frequencies. This concept is called Multiple Access. CDMA employs spread-spectrum technology and a special coding scheme where each transmitter is assigned a code to allow multiple users to be multiplexed over the same physical channel. The transmission power in the handset is limited to a maximum of 6 to 7 milliwatts [4].

Frequency is the rate at which electromagnetic fields change direction, and is measured in Hertz (Hz). One megahertz $(\mathrm{MHz})$ is one million cycles per second. 
Analogue telephones use frequencies between 800 and $900 \mathrm{MHz}$, digital telephones use frequencies between 1800 and $1990 \mathrm{MHz}$, while microwave ovens use a frequency of $2450 \mathrm{MHz}$. Today's mobile telephones, with a total power output of $2 \mathrm{~W}$, are estimated to produce insignificant local heating, and are believed to be unlikely to produce any deleterious effects.

Skin serves as a barrier for the absorption of serious hazardous materials found in the environment [5]. In skin, normal cell function depends on the presence of an intact cell membrane, which itself can serve as a target for many toxic factors.

\section{Materials and Methods}

The materials used during the research included:

a) 26 Wistar Rats

b) 2 Plexi cages, shown on Plate A and Plate B.

c) Plain Tube

d) EDTA Bottle

e) Digital weighing balance

f) Veterinary thermometer

g) $3 \mathrm{G}$ cell phone

h) Zenker's Fluids

i) $10 \%$ neutral buffered formalin

A total of 26 Wistar rats (2 weeks-old, each weighing $40 \mathrm{~g}$ at the time of experiment) were used. They were maintained under a control room with water and feed administered adlibitum.

The animals were divided into two experimental groups by random selection: Group A (Exposed) and Group B (Control) each with 13 Wistar Rats kept inside a plexi cage. The signal strength of the $3 \mathrm{G}$ was $-83 \mathrm{dBm}$ to $-75 \mathrm{dBm}$. It was kept $4 \mathrm{~cm}$ from the base of the flexi cage. The exposure was for 22 hour per day. Both groups were kept under a control room separated by a distance of $6 \mathrm{~m}$.

All animals were generally anesthetized with Ketamine injectionas shown on Plate $\mathrm{C}$ and then decapitated. The skin tissue was excised from the dorsal area and eyes samples were taken from all the rats by enucleating of the eye balls, fixedin $10 \%$ neutral buffered formalin for a minimum of 72 hours before processing through a graded alcohol and xylene was used as a clearing agent, embedded in paraffin blocks, Plate D.

Tissues were sectioned at $5 \mu \mathrm{m}$ thick and routinely stained with hematoxylin/eosin. Mounted slides were examined and photographed using a light microscope according to the method outline by Baker et al., [6].

\section{Results}

The mean temperatures with their standard deviations of the exposed and control groups are shown on Figure 1. The skin of rats in the control group B, showed histomorphologically normal epidermal epithelium and hair follicle with 
no observable lesion, Plate 1.

The skin of rats (Sample A) exposed to electromagnetic (EM) fields (mobile phone) radiation for 2 months revealed mild to severe orthokeratotic hyperkeratosis, Plate 2.

The skin of rats (Sample A) exposed toelectromagnetic (EM) fields radiation for 3 months, showed on Plate 3, moderate to severe orthokeratotic hyperkeratosis Haematoxylin and Eosin ( $\mathrm{H}$ and $\mathrm{E})$.

The eye of rats in the control group sample B showed no observable lesion with histopathologically normal sclera and retina ( $\mathrm{H}$ and $\mathrm{E}$ ). This is shown on Plate 4.

Plate 5 shows the eyes of rats (Sample A) exposed to electromagnetic (EM) fields radiation for 2 months, which revealed loss of striations in the sclera and the retina showed necrosis of the layer of rods and cones as well as the necrosis of the outer plexiform layer ( $\mathrm{H}$ and $\mathrm{E})$.

Plate 6 shows the eyes of rats (Sample A) exposed to electromagnetic (EM) fields radiation for 3-month revealing loss of striations in the sclera whereas the retina showed necrosis of the layer of rods and cones as well as the necrosis of the outer plexiform layer, ( $\mathrm{H}$ and $\mathrm{E})$.

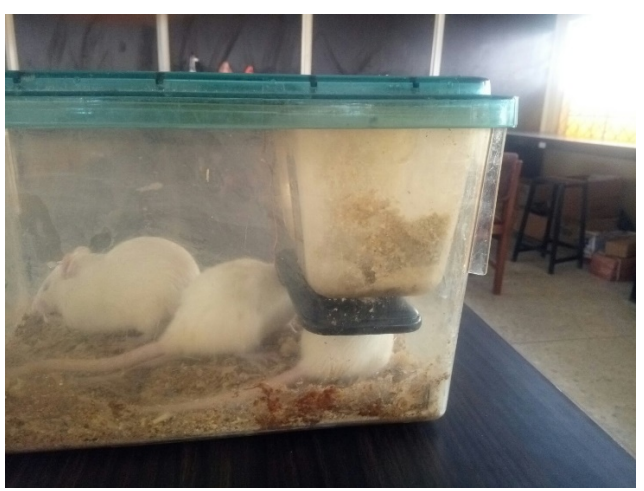

Plate A. Specimen A (exposed).

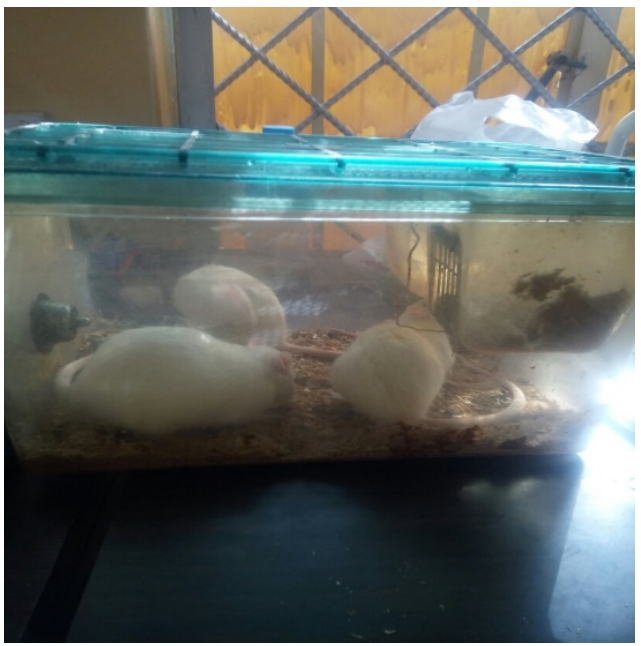

Plate B. Specimen B (control). 


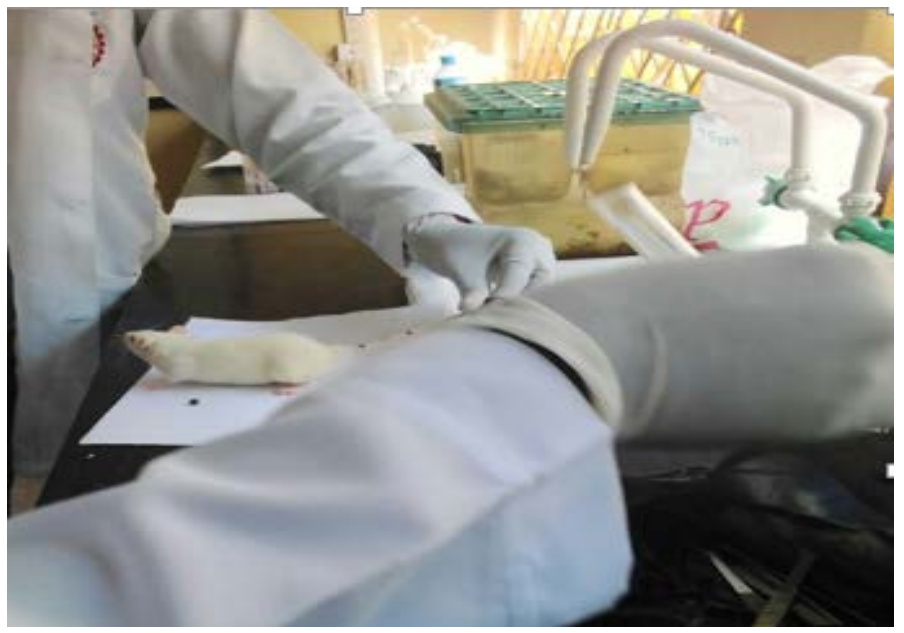

Plate C. Rat anesthetized with Ketamine injection.

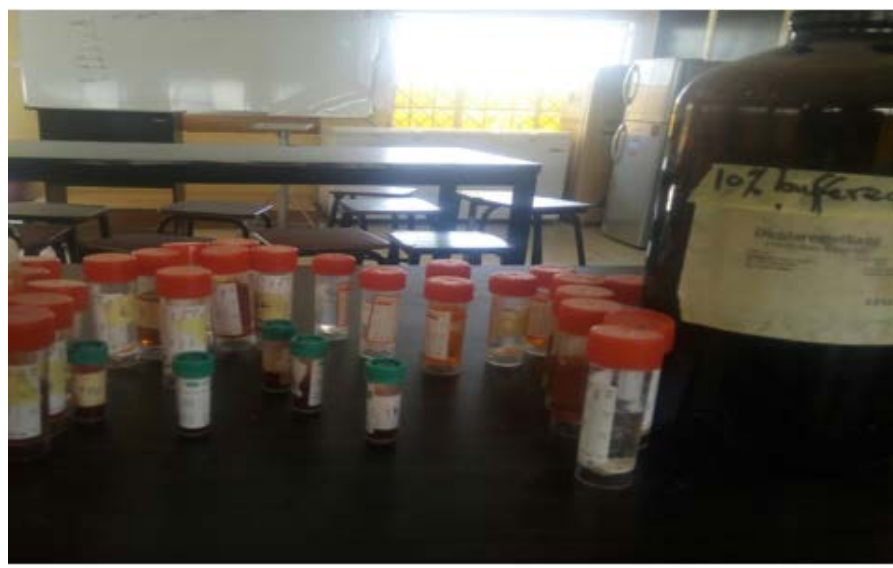

Plate D. Skin and eyes samples taken from all animals, fixed in a $10 \%$ neutral buffered formalin.

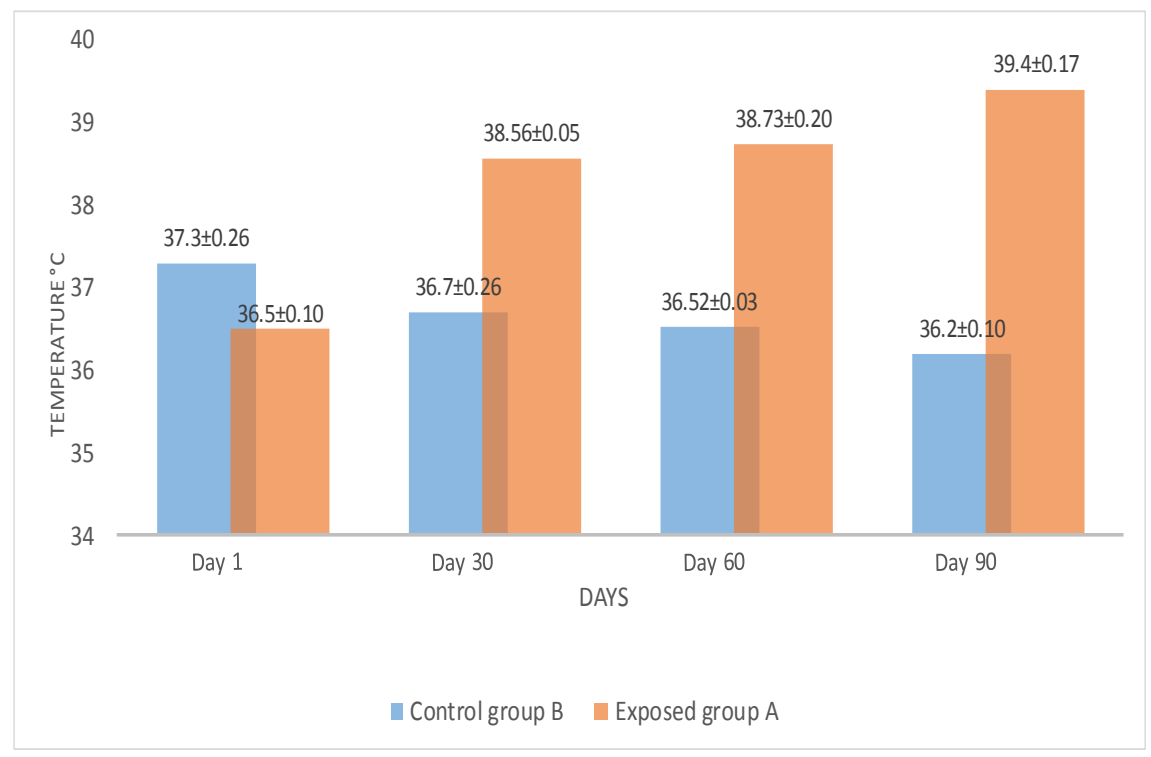

Figure 1. Temperature of exposed group A and control group B. 


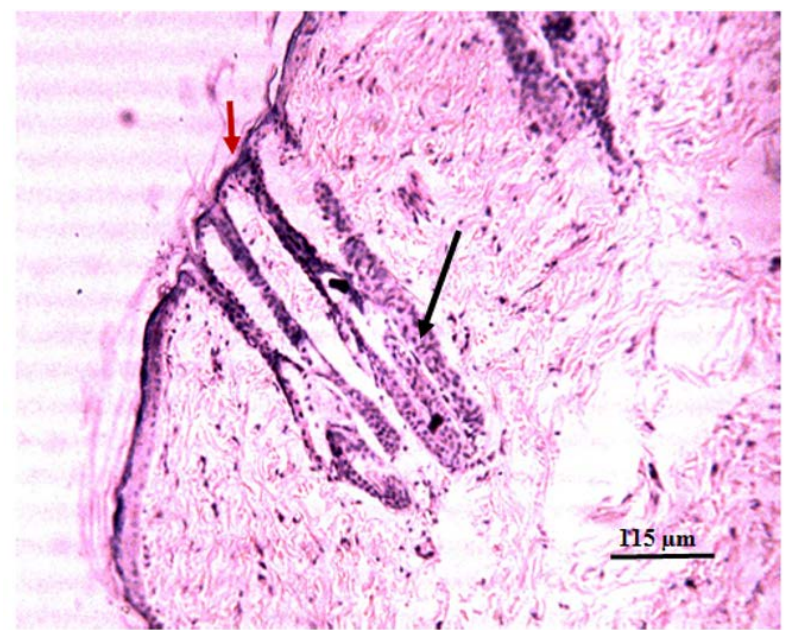

Plate 1. Photomicrograph of skin of rat showing no observable lesion, with histomorphologically normal hair follicle $(\downarrow)$ and normal keratin layer $(\downarrow)$ ) (H \& E).

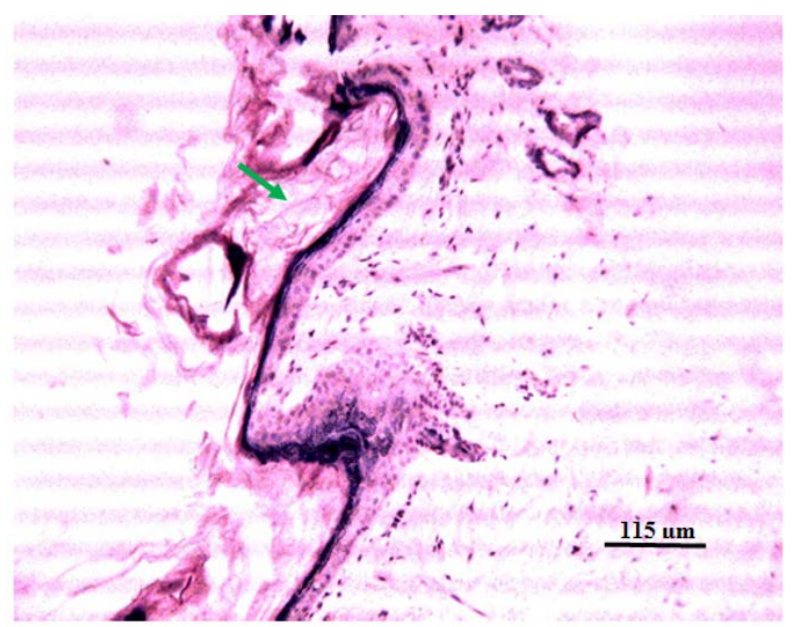

Plate 2. Photomicrograph of skin of rat exposed to $3 \mathrm{G}$ radiation for two months showing severe orthokeratotic hyperkeratosis $(\rrbracket)(\mathrm{H} \& \mathrm{E})$.

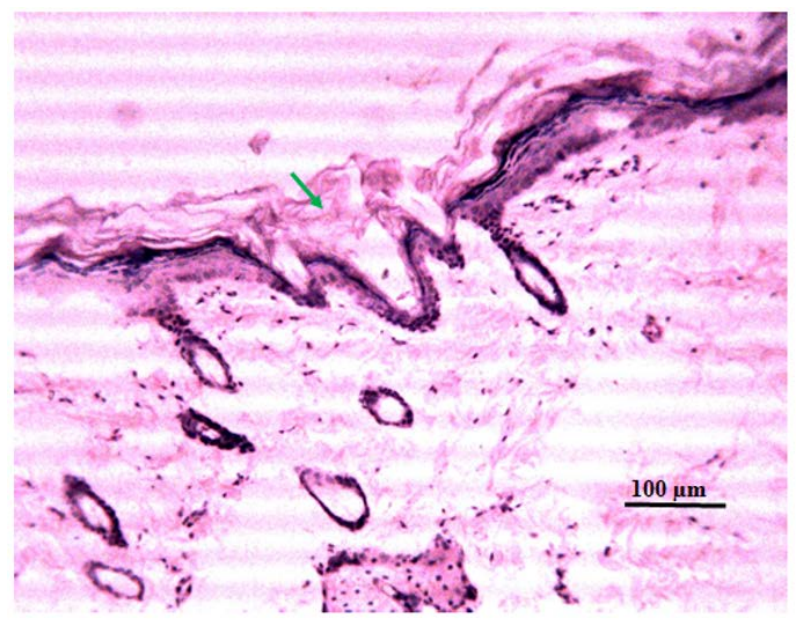

Plate 3. Photomicrograph of skin of rat exposed to $3 \mathrm{G}$ radiation for three months showing severe orthokeratotic hyperkeratosis $(\downarrow)(\mathrm{H} \& \mathrm{E})$. 


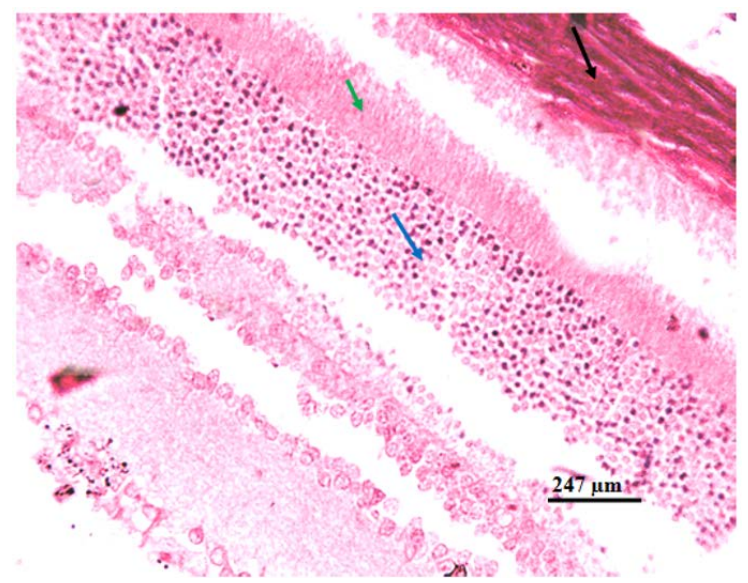

Plate 4. Photomicrograph of eye of rat showing no observable lesion, with histomorphologically normal sclera $(\downarrow)$, outer plexiform layer $(\downarrow)$ and outer nuclear layer $(\downarrow)$ (H \& E).

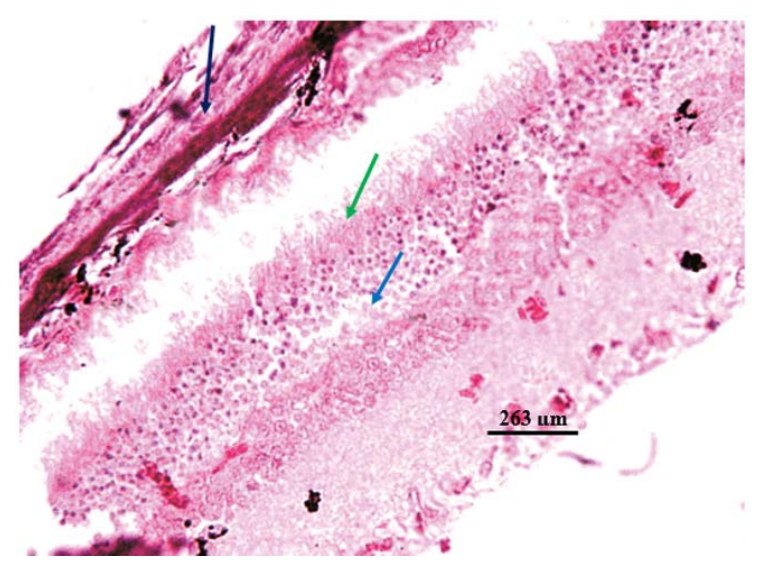

Plate 5. Photomicrograph of eye of rat exposed to $3 \mathrm{G}$ radiation for two months showing Zenker's necrosis of the sclera $(\downarrow)$, loss of striated projections at the outer plexiform layer $(\downarrow)$ with severe depletion of the cell of the outer nuclear layer $(\downarrow)(\mathrm{H} \& \mathrm{E})$.

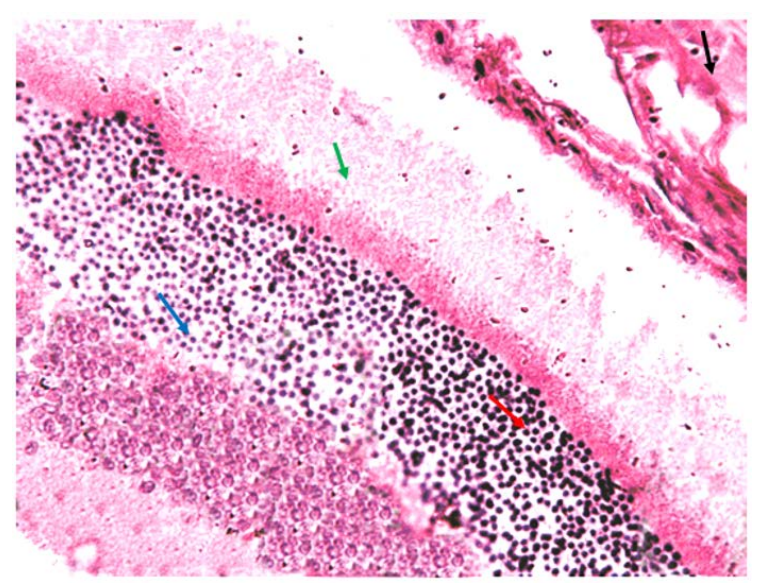

Plate 6. Photomicrograph of eye of rat exposed to 3G radiation for three months showing Zenker's necrosis of the sclera $(\downarrow)$, loss of striated projections at the outer plexiform layer $(\downarrow)$ severe depletion of the cell of the outer nuclear layer $(\downarrow)$ with severe hyperchromatosis $(\downarrow)(\mathrm{H} \& \mathrm{E})$. 


\section{Discussion and Implication of Results}

Following the exposure of mobile phone on the Wistar rat, when electromagnetic radiation passes from one medium to another, it can be reflected, refracted, transmitted or absorbed depending on the biological system and frequency of radiation, [7].

Skin serves as a barrier for the absorption of serious hazardous materials found in the environment [5]. In skin, normal cell function depends on the presence of an intact cell membrane, which itself can serve as a target for many toxic factors.

The differences in Photomicrograph of eyes of rats showed different layers of retina, this might be due to different cellular responses to EMF as cells might be trying to rebalance their growth and differentiation rate, [8]. On continuing the exposure, we found that the total retinal thickness in $3 \mathrm{G}$ group increased on $60^{\text {th }}$ and $90^{\text {th }}$ day. However, $3 \mathrm{G}$ group showed highly significant decrease in total retinal thickness on these days. It was in accordance with the findings of D'Silva et al. [9]. The increased intercellular spaces in the retinal layers might be due to shrinkage of cells or it might be due to cell death caused by subchronically exposure of wistar rats to RF radiation that resulted in oxidative stress rendering the cells vulnerable to damaging effects of RF radiation, [10]. The differences in Photomicrograph of eyes of rats showed the amount of damage caused by radiation [11]. Oxidative stress is an important factor in the pathophysiology of this effect, which usually causes fibrosis [12].

\subsection{Implication of Temperature}

Due the general principle of interaction between the cell phone radiation and dielectric (water) molecules, it is expected that the temperature should be increased. This was however, observed every irradiation session during the research. The temperature increased between ranges of $0.2^{\circ} \mathrm{C}-0.6^{\circ} \mathrm{C}$ can caused micro thermal effect in cellular and subcellular levels. The results of this study and International Commission of Non-ionization Radiation Protection (ICNIRP) reports showed the people who spend more than 50 minutes a day using a cell phone could have early dementia or other thermal damage due to the burning of glucose in the brain [13].

\subsection{Implication on Eyes}

This change is probably due to natural cell death or apoptosis that normally happens in ganglion cell layer towards the end of gestation. This probably would have resulted in decreased thickness of inner plexiform layer due to loss of synaptic contact between ganglion cells and cells of inner nuclear layer. These changes show an early onset of maturation of retina in exposed groups than the control group [9] [13].

\subsection{Implication on Skin}

It is known that the effect and the amount of damage caused by radiation are 
positively correlated with exposure time [11]. Oxidative stress is an important factor in the pathophysiology of this effect, which usually causes fibrosis [12].

The irradiated group showed an increased thickness of the stratum corneum, atrophy of the epidermis, papillomatosis, an enhanced level of basal cell proliferation, an increased thickness of the granular cell layer [14].

\section{Conclusion and Recommendation}

In our study, control group showed no significant in both eyes and skin of rats while there are some changes in the exposed group

Whether the reported structural changes in eye are reversible or not upon withdrawal of radiation source from $3 \mathrm{G}$ cell phone requires further study. The upcoming new generation phones ( $4 \mathrm{G}$ and $5 \mathrm{G}$ ) widens the scope for future investigations to find out their possible effects on developing tissues and to compare it with other existing network systems [14].

Finally, some research studies indicated no clear association was found between the exposure to the EMF radiation and biological effects. One of the important reasons for the work presented in this paper is to answer the question of whether the use of $3 \mathrm{G}$ cell phone is harmful for users or not [14]. However, the research presented in this paper has not entirely answered the question. More long term studies are needed. What we could conclude is that heavy cell phone could be under high risk of negative effects due to the exposure of EMF radiation. This conclusion indicate that caution is needed when using cell phones and more research is necessary for risk assessment based on higher number of long-term users.

\section{Conflicts of Interest}

The authors declare no conflicts of interest regarding the publication of this paper.

\section{References}

[1] Mokarram, P., Sheikhi, M., Mortazavi, S.M.J., Saeb, S. and Shokrpour (2017) Effect of Exposure to $900 \mathrm{MHz}$ GSM Mobile Phone Radiofrequency Radiation on Estrogen Receptor Methylation Status in Colon Cells of Male Sprague Dawley Rats. Journal of Biomedical Physics Engineering, 7, 79-86.

[2] Ayeni, A.A., Braimoh, K.T. and Ayen, O.B. (2011) Effect of GSM Phone Radiation on Human Pulse Rate (Heartbeat Rate). Journal of Emerging Trends in Computing and Information Sciences, 2.

[3] Ashraf, A.A., Safaai, B.D. and Nazar, Z. (2009) Research Review on the Biological Effect of Cell Phone Radiation on Human. https://ieeexplore.ieee.org/abstract/document/4781774/

[4] Bhargava, K., Balachandrudu, K.E. and Nageswar, P. (2013) Mobile Phone Radiation Effects on Human Health. International Journal of Computational Engineering Research, 3.

[5] Kanikkannan, N., Locke, B.R. and Singh, M. (2002) Effect of Jet Fuels on the Skin Morphology and Irritation in Hairless Rats. Toxicology, 175, 35-47. 
[6] Baker, J., Silverton, R.E. and Pallister, C.J. (2000) Dehydration, Impregnation, Embedding Technique and Section Preparation. Introduction to Medical Laboratory Technology, 7th Edition, 199-242.

[7] Dabo, G. and Songden, S.D. (2014) Effect of GSM Radiation on White Blood Cells. Advances in Life Science and Technology, 24, 130-139.

[8] Al Qudsi, S.A. (2012) Effect of Electromagnetic Mobile Radiation on Chick Embryo Development. Life Science Journal, 9, 983-991.

[9] D’Silva, M.H., Swer, R.T., Anbalagan, J. and Rajesh, B. (2015) Effect of Ultra High Frequency Radiation from 2G \& 3G Cell Phone on Histology of Chick Embryo Retina-A Comparative Study. International Journal of Science and Research (IJSR), 4, 2319-7064.

[10] Rijied, H.D. and Anbalagan, T.S. (2014) Histological Study of Chick Embryo Retina Exposed to Radiofrequency Radiation Emitted from 2G Cell Phone. International Journal of Science and Research, 3, Paper ID: SEP14700. http://www.ijsr.net

[11] Moustafa, Y.M., Moustafa, R.M. and Belacy, A.L. (2001) Effects of Acute Exposure to the Radiofrequency Fields of Mobile Phones on Plasma Lipid Peroxidase and Antioxidase Activities in Human Erythrocytes. Journal of Pharmaceutical Biomedical Analyses, 26, 605-608. https://doi.org/10.1016/S0731-7085(01)00492-7

[12] Somosy, Z. (2000) Radiation Response of Cell Organelles. Micron, 2, 165-181. https://doi.org/10.1016/S0968-4328(99)00083-9

[13] Moradi, M., Naghdi, N., Hemmati, H. and Asadi, S. (2016) Effects of Ultra High Frequency Mobile Radiation on Human Health. Electron Physician, 8.

[14] Ozguner, F., Aydin, G., Mollaoglu, H., Gokalp, O., Koyu, A. and Cesur, G. (2004) Prevention of Mobile Phone Induced Skin Tissue Changes by Melatonin in Rat: An experimental Study. Journal of Toxicology and Industrial Health, 20, 133-139. https://doi.org/10.1191/0748233704th207oa 